\title{
mRCC Outcome in the Treatment of Metastatic Renal Cell Carcinoma - A German Single-center Real-world Experience
}

\author{
MARIA SCHWAB*, RAINER HOFMANN, HENDRIK HEERS and AXEL HEGELE* \\ Department of Urology and Pediatric Urology, University Medical Center, Marburg, Germany
}

\begin{abstract}
Background/Aim: Since the advent of targeted therapeutics, paradigms in metastatic renal cell carcinoma $(m R C C)$ treatment have changed. We investigated if efficacy and safety data from randomized controlled trials can be transferred into real-world settings. Patients and Methods: All patients with mRCC treated from 2006-2015 at the Department of Urology (Marburg-Germany) were retrospectively analyzed. Collected data include: Patient demographics, tumor characteristics, efficacy, safety, and used therapy sequences. Results: In total, 197 patients with mRCC were identified. About one third of patients reached third-line therapy. Median overall survival in real-world amounted to 25.8 months with a five-year survival rate of $30 \%$ with significant differences between IMDC risk groups $(p<0.01)$. Response rates were highest using tyrosine kinase inhibitor (TKI). Patients with response to therapy showed significantly improved survival $(p<0.05)$. Side-effects in each therapy line were manageable in daily practice. Conclusion: Our data suggest that targeted therapy in the treatment of $m R C C$ is effective and safe in daily clinical practice and for real-world patients.
\end{abstract}

Renal cell carcinoma (RCC) is the third most common urological malignant tumor after prostate and urothelial carcinoma. According to data from the Robert-KochInstitute, RCC had an incidence in Germany of 14,956 patients in 2014 with a high mortality rate of 5,278 patients (1). The prognosis of RCC patients heavily depends on the

This article is freely accessible online.

*These Authors contributed equally to this study.

Correspondence to: Maria Schwab, Department of Urology and Pediatric Urology, Baldingerstrasse, University Medical Center, D35033 Marburg, Germany. Tel: +49 064215862479, e-mail: schwab.maria@gmx.de

Key Words: Real-world experience, renal cell carcinoma, targeted therapy. time of diagnosis. Early detection of localized disease offers the opportunity of curative e.g. surgical treatment. In case of metastatic RCC (mRCC) there is usually no curative treatment available. Only for a small number of patients, surgical resection of metastases is reasonable (2). Until 2006, mRCC was treated using unspecific immunotherapeutic drugs like interleukin and interferon with high toxicity and limited overall survival (OS) of about 13 months (3). Since the advent of new therapeutic agents in 2006, targeting different tumor pathways like the vascular endothelial growth factor/receptors or the mammalian target of rapamycin (mTOR), mRCC treatment has improved distinctly. According to pivotal clinical trials, response rates were enhanced and the toxicity profile using the approved drugs in a sequential manner was optimized. For randomized clinical trials, an "optimized" population was selected and subgroups of patients were ineligible due to old age, comorbidities, or reduced performance status. Nevertheless, in real-life, these patients also receive treatment and data about outcome and safety are limited in mRCC.

In our single-center study, the real-life outcome of mRCC patients was evaluated over a period of 10 years after implementation of targeted therapy with regard to change of treatment patterns, outcome, and safety profile.

\section{Patients and Methods}

In our retrospective data analysis, every patient with mRCC who received treatment between January 2006 and December 2015 at the Department of Urology and Pediatric Urology, Phillips University Marburg (Germany), was enrolled. The collected data included patient characteristics (gender, age, performance status), histological type, tumor characteristics, disease stage at diagnosis, type of received treatment, therapy efficacy, therapy-associated side effects, and used sequences of the respective targeted agents. Data were collected using the clinical data system ORBIS ${ }^{\circledR}$ and the patient files. The patients were stratified into favorable, intermediate, and poor risk group, respectively, according to IMDC criteria (4).

Treatment efficacy was analyzed on the basis of objective response rate (ORR), disease control rate (DCR) and progressive disease (PD), progression-free survival (PFS), and overall survival (OS). For patients still alive at last follow-up, OS was censored at 
this date. We assessed the extent of safety based on the occurrence of toxicity grade 3 or 4 under treatment. Severity of toxicity was assessed by the physician in charge, according to Common Toxicity Criteria in Adverse Events (5) in the current version, whenever there was physician-patient consultation.

Statistical analyses were conducted using GraphPad Prism version 6.01 and SPSS Statistics version 24.0. KolmogorovSmirnov test or Chi-squared test was performed before every analysis to assess if Gaussian distribution could be assumed. Survival functions were estimated using the Kaplan-Meier method and compared overall survival with Mann-Whitney $U$-test, KruskalWallis test, $t$-test, and one-way ANOVA, respectively, where applicable. A $p$-value $\leq 0.05$ was assumed as statistically significant.

\section{Results}

Patient data. In the above-mentioned time period, 197 patients with mRCC were identified of whom 124 in total received systemic treatment and were included in the study (98 male, 26 female, median age 67 years, $79 \%$ cc mRCC). As prior therapy, $91 \%(n=113)$ of the patients received radical nephrectomy or nephron-sparing surgery, respectively. Synchronous metastatic spread was detected in $48 \%(n=60)$ of the patients. Metachronous metastases became manifest in $52 \%(n=64)$ of the patients after a median of 21.9 months following primary curative surgery.

According to the IMDC criteria, $13.7 \%(n=17)$ of the patients were stratified into the favorable risk group, $63.3 \%$ $(\mathrm{n}=79)$ intermediate risk, and $22.6 \%(\mathrm{n}=28)$ poor risk. Table I shows baseline characteristics.

Therapy lines and sequences. After first line therapy, second line therapy was initiated in $60 \%$ of patients, third line therapy in $33 \%$ and fourth line therapy in $21 \%$ of patients triggered by radiographic disease progression. Over the course of ten years, the selection of therapeutic agents changed as new substances became available. In first-line therapy, $74.2 \%$ of the patients received TKI, $4.8 \%$ mammalian target of rapamycin inhibitor (mTORi), $8.9 \%$ bevacizumab, and $12.1 \%$ interferon alpha-based immunotherapy. Over the ten-year time period, the application of several drugs changed and in 2015, all patients received a TKI as first line therapy. In daily clinical practice, the most often applied sequence towards second line therapy was TKI-mTORi $(45.6 \%)$ followed by TKI-TKI $(22.6 \%)$. Towards the third line therapy, TKI-mTORi-TKI was the most commonly used sequence $(34.1 \%)$ followed by TKITKI-mTORi $(26.8 \%)$. The remaining patients were pretreated with interferon alpha-based immunotherapy or received only single TKI or mTORi treatment, respectively.

Efficacy. The median follow-up was 21.3 months with a range from 0.9 to 105.0 months. At the last follow-up, 21 patients were still alive and 32 patients were censored. The median PFS was 6.8 months, 3.4 months and 1.7 months,
Table I. Baseline characteristics of the study population including type of first-line therapy and best response to therapy.

\begin{tabular}{lc}
\hline & $\%(\mathrm{~N})$ \\
\hline Median age at therapy initiation & 67.0 \\
Gender & \\
Male & $79.0(98)$ \\
Female & $21.0(26)$ \\
Karnofsky Performance Status & \\
$\geq 80$ & $83.9(104)$ \\
$<80$ & $16.1(20)$ \\
Histological type & \\
Clear cell RCC & $79.9(99)$ \\
Non-clear cell RCC & $14.5(18)$ \\
Unknown & $5.6(7)$ \\
Prior nephrectomy/nephron-sparing surgery & \\
Yes & $91.1(113)$ \\
No & $8.9(11)$ \\
IMDC risk group & \\
Favorable risk & $13.7(17)$ \\
Intermediate risk & $63.7(79)$ \\
Poor risk & $21.8(28)$ \\
Metastatic spread & \\
Synchronous & $48.4(60)$ \\
Metachronous & $51.6(64)$ \\
Type of first-line therapy & \\
Sorafenib & $8.2(10)$ \\
Sunitinib & $38.9(48)$ \\
Pazopanib & $27.6(34)$ \\
Everolimus & $0.01(1)$ \\
Temsirolimus & $4.1(5)$ \\
Bevacizumab & $8.9(11)$ \\
Unspecific immunotherapy & \\
Best response to therapy & $34.7(4)$ \\
Complete response & $34.7(43)$ \\
Partial response & $27.4(34)$ \\
Stable disease \\
Progressive disease & \\
& \\
& \\
& \\
&
\end{tabular}

respectively, for first, second, and third line therapy. Median OS was 25.8 months and five-year survival rate $30.6 \%$. Median OS showed a significant correlation to the risk group according to IMDC criteria $(p<0.01)$. Patients with favorable risk had an improved median overall survival with 72.0 months compared to the intermediate and poor risk group with 28.7 months and 7.3 months, respectively $(p<0.01)$ (Figure 1).

Patients with synchronous mRCC showed significantly decreased median OS compared to patients with metachronous metastatic spread (21.1 months vs. 49.0 months, $p=0.057$ ) as well as a worse five-year relative survival rate without reaching statistical significance (17.1\% vs. $43.9 \%)$.

Drug-efficacy. Regardless of therapy line, tyrosine kinase inhibitors presented better ORR (complete response; partial response) (pazopanib 33\% (0\%; 33\%), sorafenib 21\% (2\%; 


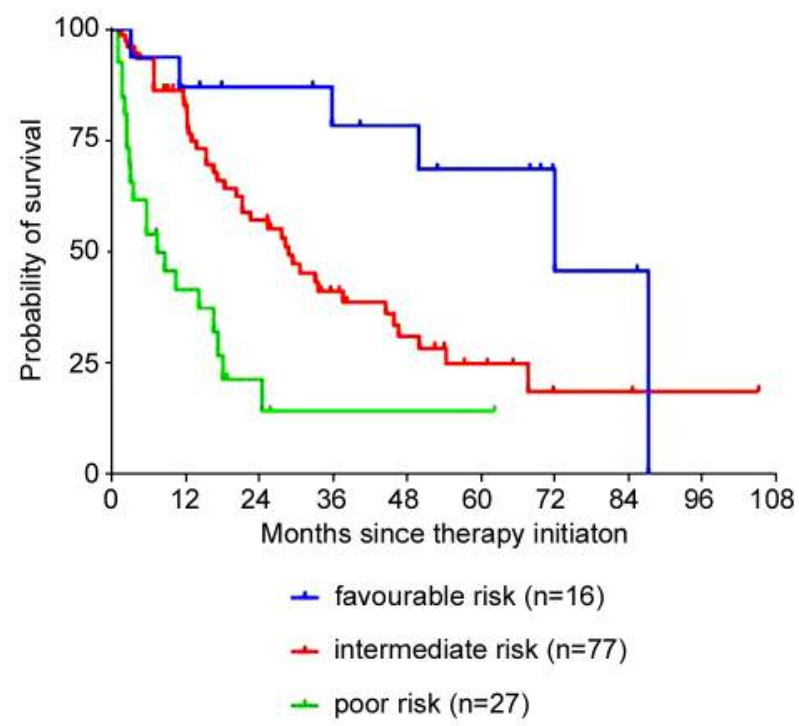

Figure 1. Overall survival (Kaplan-Meier) for mRCC plotted against the IMDC risk groups: The median overall survival was 72.0 months for patients with favorable risk ( $n=17, H R=1.94,95 \% C I=1.20-2.77)$, 28.7 months for patients with intermediate risk $(n=79, H R=1.02$, 95\%CI=0.84-1.23), and 7.3 months for those with poor risk $(n=28$, $H R=0.46,95 \% C I=0.28-0.64, p<0.01)$.

$19 \%)$, sunitinib $27 \%(4 \% ; 23 \%)$ ) compared to mTOR inhibitors (everolimus $7 \%(0 \% ; 7 \%)$, temsirolimus 5\% $(0 \%$; $5 \%)$ ). Likewise, DCR (complete response; partial response; stable disease) was better under TKI therapy (pazopanib 69\% $(0 \% ; 33 \%$; 36\%), sorafenib $46 \%(2 \% ; 19 \% ; 25 \%)$, sunitinib $59 \%(4 \% ; 23 \% ; 32 \%)$ ) than under mTORi therapy (everolimus $41 \%(0 \% ; 7 \% ; 34 \%)$, temsirolimus $50 \%(0 \%$; $5 \% ; 45 \%)$ ). Patients with stable (SD) or progressive disease (PD) had a significantly worse OS (29.4 months and 4.9 months, respectively) compared to those with complete (CR) or partial response (PR) (median OS not reached and 45.9 months, respectively, $p<0.05)$ at any time during their therapy (Figure 2).

Non-clear cell RCC. In patients with non-clear cell histology $(\mathrm{n}=18)$, including papillary and sarcomatoid variants, median OS was significantly inferior compared to clear cell histology $(\mathrm{n}=99,16.5 v s .30 .6$ months, $p<0.05)$ (Figure 3). Accordingly, non-clear cell histology was also associated with lower ORR and DCR regardless of the drug applied (ORR 22.2\% vs. $42.4 \%$ and DCR $50.0 \%$ vs. $78.8 \%$, respectively).

Toxicity. Across the different therapy lines, no accumulation or increase of significant toxicities (grade 3 and 4) could be observed: first-line therapy $25 \%$, second line therapy $23 \%$,

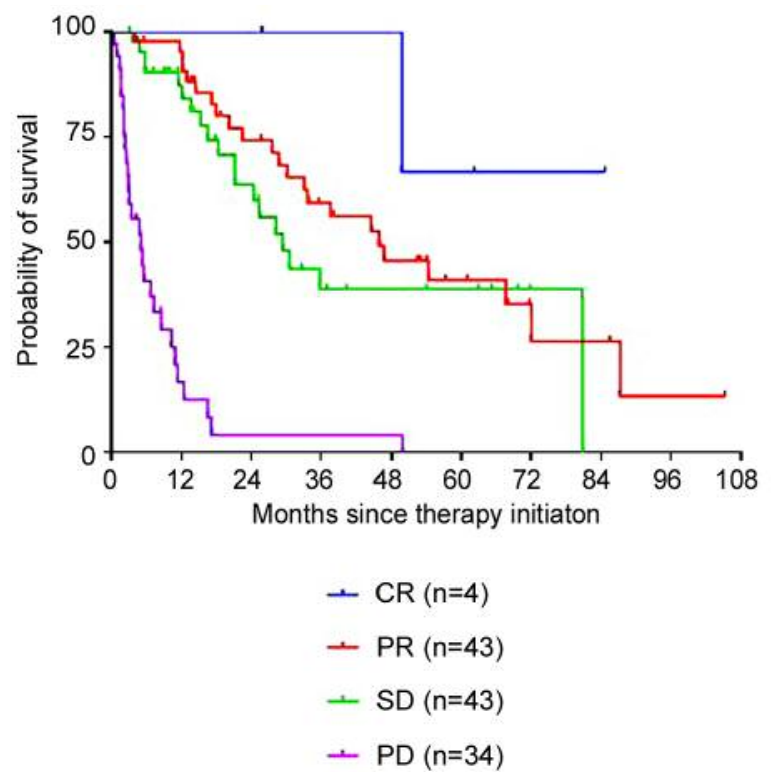

Figure 2. Overall survival (Kaplan-Meier) for mRCC plotted against the response rates. The median overall survival was not reached for patients whose best response was complete (CR), 45.9 months for partial response $(P R)(n=47, H R=1.54,95 \% C I=1.20-1.91), 29.4$ months for stable disease $(S D)(n=43, H R=0.94,95 \% C I=0.73-1.21)$, and 4.9 months for progressive disease $(n=34 ; H R=0.31,95 \% C I=0.19$ $0.46, p<0.05)$.

third-line therapy 20\%. Clinical performance status decreased with proceeding therapy lines $(55.6 \%$ ECOG 0 in first line treatment, $43.2 \%$ ECOG 0 in second line treatment, $36.6 \%$ ECOG 0 in third line treatment).

\section{Discussion}

Over the past decade, the treatment of mRCC changed rapidly. With the introduction of new drugs targeting different tumor pathways and the advent of sequential therapy options, OS is significantly improved. Nevertheless, in daily clinical practice, many patients require treatment that would not fit the inclusion criteria for clinical trials (6). Thus, it is interesting to compare the outcome and safety data of real-world patients to the results from clinical trials.

In our real-life population, the median OS was 25.8 months with a five-year survival rate of $30.6 \%$. Sixty percent of patients reached second line and 30\% third line therapy with most commonly used sequences being TKI-mTORi (45.6\%) and TKI-TKI-mTORi (34.1\%) respectively. Median PFS was 6.8 months, 3.4 months and 1.7 months, respectively, for first-line, second-line and third-line treatment. These data are in keeping with other real-life data (6-9). PFS was comparable - median OS was mentioned in two studies. One registry-based analysis showed a median 


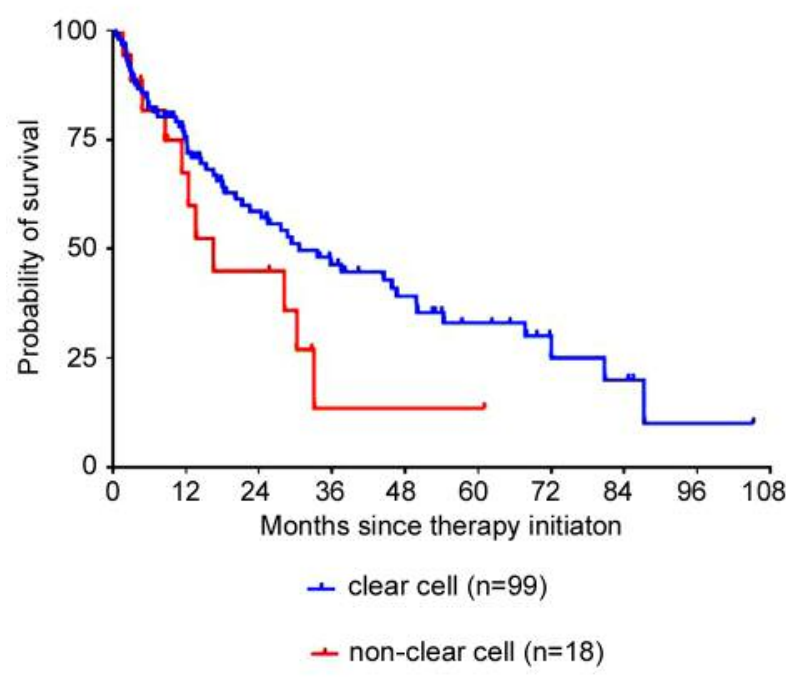

Figure 3. Overall survival (Kaplan-Meier) for mRCC plotted against the histological subtype: The median overall survival was 30.6 months for patients with clear cell RCC ( $n=99, H R=1.07,95 \% C I=0.88-1.29)$ and 16.5 months for those with non-clear cell $R C C(n=18, H R=0.61$, 95\% CI=0.43-0.93, $p<0.05$ ).

OS of 33.2 months, the other study found a shorter median OS of 18 months $(6,9)$. Compared to phase III clinical trial data showing median OS from 10.9 to 26.4 months and median PFS from 5.5 to 11.0 months in first-line treatment, we can achieve similar efficiency in the real-life setting today (10-13). Less is known about the outcome of patients in consecutive therapy lines. In our cohort, $60 \%$ and $33 \%$ reached second line and third line therapy, respectively. This is in contrast to a real-life analysis with over 1000 patients of whom only $19 \%$ reached second line therapy (8). We found no plausible explanation about this in the face of similar used sequences (TKI-mTORi 33\%, TKI-TKI 27\%). Nevertheless, real-life data in third and fourth-line therapy are limited. The GOLD study assessed dovitinib versus sorafenib for third line treatment after failure of the sequence TKI-mTORi. No significant difference was evident concerning the primary study endpoint PFS (Dovitinib 3.7 months $v s$. Sorafenib 3.6 months) (14). However, if we compare these durations of response with the median PFS of 1.9 months in the placebo group from the RECORD-1 study after anti-VEGF or cytokine-based treatment failure (15), we can conclude the importance of sequential therapy. Even in third-line therapy, patients benefit from treatment as we can see in our cohort as well. In our real-world setting, PFS in third-line treatment may be shorter because it was analyzed for the entire cohort and was not divided into subgroups as done in the above-mentioned trials as well as due to the heterogeneity of the cohort and multiple kinds of pretreatment in real-life. Our study is limited by the lack of central radiology review in clinical practice and determination of PFS was at the discretion of the physician and radiologist in charge, of course referring to Response Evaluation Criteria In Solid Tumors (RECIST). Regardless, we are convinced that these trial and real-life data underline that patients should receive third-line therapy whenever applicable. In real-life patients with favorable risk according to IMDC criteria showed the longest OS with 72 months, decreasing to 28.7 months for intermediate, and 7.3 months for poor risk group $(p<0.01)$. These findings equal those of Heng et al. in an international multicenter study, including 1028 patients for external validation of the International Metastatic Renal-Cell Carcinoma Database Consortium Model (OS: favorable risk: 43.3 months, intermediate risk: 22.5 months, poor risk: 7.8 months) (4). The much longer OS of 72.0 months in our favorable risk group could be explained through the smaller number of patients in this subgroup and the use of median which could lead to overestimation in survival. Therefore, it should be interpreted with caution.

Efficacy of treatment in our real-life cohort was significantly lower in metastasized nccRCC compared to ccRCC (OS 16.5 vs. 30.6 months/ORR: 22.2\% vs. 42.4\%). Steffens and coworkers showed similar results from a retrospective German multicenter study. Patients with metastatic papillary RCC $(n=71)$ presented a significantly worse cancer-specific survival compared to metastatic clearcell RCC (17.9 months vs. 23.5 months) (16). This conflicts with the findings of Patard et al. who assessed 4063 patients retrospectively and did not find histology to be an independent prognostic variable in multivariate analysis (17). Reasons for these differences might be, due to the retrospective nature of our and the mentioned studies, the difference in magnitude of patient numbers with papillary subtypes and the missing distinction between the histological subtypes 1 and 2 which show different malignant potential $(10,18)$.

In our cohort, the use of TKI showed higher objective response rates (pazopanib 33\%, sorafenib 21\%, sunitinib $27 \%$ ) compared to mTORi (everolimus $7 \%$, temsirolimus $5 \%$ ) regardless of treatment line. These drug-dependent differences were also evident in clinical trials: pazopanib $30 \%$ (12); sorafenib $10 \%$ (11) and 31\% (19), respectively; sunitinib $31 \%$ (20); everolimus $1 \%$ (15) and temsirolimus $8.6 \%$ (10). Our data showed significantly improved survival in case of response to therapy in real-life (CR: median not reached, PR: 45.9 months, SD: 29.4 months, PD: 4.9 months, $p<0.01)$ and confirmed previous data from RECORD-3 trial recommending TKI as initial treatment in sequential therapy resulting in OS benefit (21). Nevertheless a small study $(n=89)$ focusing poor rsik mRCC showed that second-line treatment using TKI is more effective compared to usage of mTORi with significant prolonged median OS (15.0 vs. 7.6 months) (22). Adverse events (AE) grade $3 / 4$ occurred in $25 \%, 23 \%$ and $20 \%$ of patients, respectively, under first-line, 
second-line and third-line treatment. On closer consideration, a high variability in the occurrence of grade 3 or 4 side effects becomes obvious between different phase III clinical trials, even for the same therapeutic agent. In the clinical approval study for pazopanib, 33\% AE grade 3/4 were reported (23) whereas $74 \%$ of patients in COMPARZ study showed severe toxicity grade $3 / 4$ under pazopanib as well as under sunitinib (24). As already mentioned, a broad range of reported $\mathrm{AE}$ grade $3 / 4$ can be found within the literature, reaching from $33 \%$ to $74 \%(19,23-25)$, with a mean of approximately $60 \%$. In comparison, the incidence of serious side effects in our cohort is lower. Attributable to its retrospective nature and possibly insufficient documentation in daily clinical practice, it might be that the occurrence of severe toxicity grade 3 and 4 is underestimated in the present study. However, since 2006, physicians learned to manage and prevent targeted therapy-associated toxicities in daily clinical routine.

In conclusion, our data reveal that treatment of $\mathrm{mRCC}$ patients using targeted therapy is efficient and safe in the real-world setting and comparable to clinical trials data.

Further improvement in the treatment of metastatic renal cell carcinoma can be expected through the expansion of armamentarium by immune checkpoint blockade. The challenge for future trials will be the determination of optimal sequences and predictive biomarkers to offer every single patient the often quoted tailored therapy whilst keeping an eye on feasibility in clinical practice.

\section{Acknowledgements}

The Authors thank Bettina Seifert-Heinze for her support in data registration.

\section{References}

1 Robert Koch-Institut. Krebs - Datenbankabfrage. https://www.krebsdaten.de/Krebs/SiteGlobals/Forms/Datenbanka bfrage/datenbankabfrage_stufe2_form.html

2 Friedel G, Hürtgen M, Penzenstadler M, Kyriss T and Toomes $\mathrm{H}$ : Resection of pulmonary metastases from renal cell carcinoma. Anticancer Res 19(2C): 1593-1596, 1999.

3 Coppin C, Porzsolt F, Awa A, Kumpf J, Coldman A and Wilt T: Immunotherapy for advanced renal cell cancer. Cochrane Database Syst Rev (1): CD001425, 2005.

4 Heng DYC, Xie W, Regan MM, Harshman LC, Bjarnason GA, Vaishampayan UN, Mackenzie M, Wood L, Donskov F, Tan MH, Rha SY, Agarwal N, Kollmannsberger C, Rini BI and Choueiri TK: External validation and comparison with other models of the International Metastatic Renal-Cell Carcinoma Database Consortium prognostic model. A population-based study. Lancet Oncol 14(2): 141-148, 2013.

5 NIH - National Cancer Institute. Common Terminology Criteria for Adverse Events (CTCAE) I Protocol DevelopmentlCTEP https://ctep.cancer.gov/protocolDevelopment/electronic_applicati ons/ctc.htm\#ctc_40
6 Marschner N, Staehler M, Müller L, Nusch A, Harde J, Koska M, Jänicke $M$ and Goebell PJ: Survival of patients with advanced or metastatic renal cell carcinoma in routine practice differs from that in clinical trials - analyses from the German clinical RCC registry. Clin Genitourin Cancer 15(2): e209-e215, 2017.

7 Biondani P, Verzoni E, Torri V, Porcu L, Grassi P, Paolo T, Braud $F$ and Procopio G: Sequential Tyrosine Kinase Inhibitors (TKIs) in metastatic renal cell carcinoma. Results from a large cohort of patients. Anticancer Res 34(5): 2395-2398, 2014.

8 Maroun R, Mitrofan L, Benjamin L, Nachbaur G, Maunoury F, Le Jeunne $P$ and Durand-Zaleski I: Real life patterns of care and progression free survival in metastatic renal cell carcinoma patients. Retrospective analysis of cross-sectional data. BMC Cancer 18(1): 214, 2018.

9 Poprach A, Fiala O, Chloupkova R, Melchiar B, Lakomy R, Petrakova K, Zemanova M, Kopeckova K, Slaby O, Studentova H, Kopecky J, Kiss I, Finek J, Dusek L and Buchler T: Pazopanib for metastatic renal cell carcinoma: a registry-based analysis of 426 patients. Anticancer Res 38(1): 449-456, 2018

10 Hudes G, Carducci M, Tomczak P, Dutcher J, Figlin R, Kapoor A, Staroslawska E, Sosman J, McDermott D, Bodrogi I, Kovacevic Z, Lesovoy V, Schmidt-Wolf IG, Barbarash O, Gokmen E, O'Toole T, Lustgarten S, Moore L and Motzer RJ: Temsirolimus, interferon alfa, or both for advanced renal-cell carcinoma. N Engl J Med 356(22): 2271-2281, 2007.

11 Escudier B, Eisen T, Stadler WM, Szczylik C, Oudard S, Staehler M, Negrier S, Chevreau C, Desai AA, Rolland F, Demkow T, Hutson TE, Gore M, Anderson S, Hofilena G, Shan M, Pena C, Lathia C and Bukowski RM: Sorafenib for treatment of renal cell carcinoma. Final efficacy and safety results of the phase III treatment approaches in renal cancer global evaluation trial. J Clin Oncol 27(20): 3312-3318, 2009.

12 Sternberg CN, Davis ID, Mardiak J, Szczylik C, Lee E, Wagstaff J, Barrios CH, Salman P, Gladkov OA, Kavina A, Zarbá JJ, Chen M, McCann L, Pandite L, Roychowdhury DF and Hawkins RE: Pazopanib in locally advanced or metastatic renal cell carcinoma. Results of a randomized phase III trial. J Clin Oncol 28(6): 1061-1068, 2010.

13 Motzer RJ, Hutson TE, Tomczak P, Michaelson MD, Bukowski RM, Oudard S, Negrier S, Szczylik C, Pili R, Bjarnason GA, Garcia-del-Muro X, Sosman JA, Solska E, Wilding G, Thompson JA, Kim ST, Chen I, Huang X and Figlin RA: Overall survival and updated results for sunitinib compared with interferon alfa in patients with metastatic renal cell carcinoma. J Clin Oncol 27(22): 3584-3590, 2009.

14 Motzer RJ, Porta C, Vogelzang NJ, Sternberg CN, Szczylik C, Zolnierek J, Kollmannsberger C, Rha SY, Bjarnason GA, Melichar B, De Giorgi U, Grünwald V, Davis ID, Lee JL, Esteban E, Urbanowitz G, Cai C, Squires M, Marker M, Shi MM and Escudier B: Dovitinib versus sorafenib for third-line targeted treatment of patients with metastatic renal cell carcinoma. An open-label, randomised phase 3 trial. Lancet Oncol 15(3): 286-296, 2014.

15 Motzer RJ, Escudier B, Oudard S, Hutson TE, Porta C, Bracarda S, Grünwald V, Thompson JA, Figlin RA, Hollaender N, Urbanowitz G, Berg WJ, Kay A, Lebwohl D and Ravaud A: Efficacy of everolimus in advanced renal cell carcinoma. A double-blind, randomised, placebo-controlled phase III trial. Lancet 372(9637): 449-456, 2008. 
16 Steffens S, Janssen M, Roos FC, Becker F, Schumacher S, Seidel C, Wegener G, Thüroff JW, Hofmann R, Stöckle M, Siemer S, Schrader M, Hartmann A, Kuczyk MA, Junker K and Schrader AJ: Incidence and long-term prognosis of papillary compared to clear cell renal cell carcinoma - a multicentre study. Eur J Cancer 48(15): 2347-2352, 2012.

17 Patard J-J, Leray E, Rioux-Leclercq N, Cindolo L, Ficarra V, Zisman A, De La Taille A, Tostain J, Artibani W, Abbou CC, Lobel B, Guillé F, Chopin DK, Mulders PF, Wood CG, Swanson DA, Figlin RA, Belldegrun AS and Pantuck AJ: Prognostic value of histologic subtypes in renal cell carcinoma. A multicenter experience. J Clin Oncol 23(12): 2763-2771, 2005.

18 Pignot G, Elie C, Conquy S, Vieillefond A, Flam T, Zerbib M, Debré B and Amsellem-Ouazana D: Survival analysis of 130 patients with papillary renal cell carcinoma. Prognostic utility of type 1 and type 2 subclassification. Urology 69(2): 230-235, 2007.

19 Eichelberg C, Vervenne WL, Santis M de, Fischer von Weikersthal L, Goebell PJ, Lerchenmüller C, Zimmermann U, Bos MM, Freier W, Schirrmacher-Memmel S, Staehler M, Pahernik S, Los M, Schenck M, Flörcken A, van Arkel C, Hauswald K, Indorf M, Gottstein D and Michel MS: SWITCH. A Randomised, sequential, open-label study to evaluate the efficacy and safety of sorafenib-sunitinib versus sunitinibsorafenib in the treatment of metastatic renal cell cancer. Eur Urol 68(5): 837-847, 2015.

20 Motzer RJ, Hutson TE, Tomczak P, Michaelson MD, Bukowski RM, Rixe O, Oudard S, Negrier S, Szczylik C, Kim ST, Chen I, Bycott PW, Baum $\mathrm{CM}$ and Figlin RA: Sunitinib versus interferon alfa in metastatic renal-cell carcinoma. N Engl J Med 356(2): 115-124, 2007.

21 Motzer RJ, Barrios CH, Kim TM, Falcon S, Cosgriff T, Harker WG, Srimuninnimit V, Pittman K, Sabbatini R, Rha SY, Flaig TW, Page R, Bavbek S, Beck JT, Patel P, Cheung FY, Yadav S, Schiff EM, Wang X, Niolat J, Sellami D, Anak O and Knox JJ: Phase II randomized trial comparing sequential first-line everolimus and second-line sunitinib versus first-line sunitinib and second-line everolimus in patients with metastatic renal cell carcinoma. J Clin Oncol 32(25): 2765-2772, 2014.
22 Miyake H, Imai S, Tamura K, Sugiyama T, Furuse H, Ozono S and Fuzjisawa M: Comparison of tyrosine kinase inhibitor versus mammalian target of rapamycin inhibitor as second-line molecular-targeted therapy for patients with poor-risk metastatic renal cell carcinoma. Anticancer Res 37(3): 1523-1528, 2017.

23. Sternberg CN, Hawkins RE, Wagstaff J, Salman P, Mardiak J, Barrios CH, Zarba JJ, Gladkov OA, Lee E, Szczylik C, McCann L, Rubin SD, Chen M and Davis ID: A randomised, doubleblind phase III study of pazopanib in patients with advanced and/or metastatic renal cell carcinoma. Final overall survival results and safety update. Eur J Cancer 49(6): 1287-1296, 2013.

24 Motzer RJ, Hutson TE, Cella D, Reeves J, Hawkins R, Guo J, Nathan P, Staehler M, de Souza P, Merchan JR, Boleti E, Fife $\mathrm{K}$, Jin J, Jones R, Uemura H, De Giorgi U, Harmenberg U, Wang J, Sternberg CN, Deen K, McCann L, Hackshaw MD, Crescenzo R, Pandite LN and Choueiri TK: Pazopanib versus sunitinib in metastatic renal-cell carcinoma. $\mathrm{N}$ Engl $\mathrm{J}$ Med 369(8): 722-731, 2013.

25 Choueiri TK, Escudier B, Powles T, Tannir NM, Mainwaring PN, Rini BI, Hammers HJ, Donskov F, Roth BJ, Peltola K, Lee JL, Heng DYC, Schmidinger M, Agarwal N, Sternberg CN, McDermott DF, Aftab DT, Hessel C, Scheffold C, Schwab G, Hutson TE, Pal S and Motzer RJ: Cabozantinib versus everolimus in advanced renal cell carcinoma (METEOR). Final results from a randomised, open-label, phase 3 trial. Lancet Oncol 17(7): 917-927, 2016 